after a study of 425 cases of end-result idiopathic scoliosis, that exercise should be avoided. This study found that approximately $60 \%$ of the patients treated with exercises had an increase in the deformity, and $40 \%$ had no change.

Recent work done by Stone et al (1979), has included a ninemonth exercise therapy programme for 99 subjects with scoliosis and also reported poor results. However, the results of this study showed the extent to which, under the optimal conditions outlined, therapeutic exercises were capable of correcting functional scoliosis and a significant change in both body position and spinal functionality was shown after 20 weeks of treatment. The data revealed post-treatment values that suggested that some positive changes had taken place due to the therapeutic programme. It appears that in cases of lateral symmetries, young children have high potential for balancing the trunk muscles if the exercise intensity is well regulated and monitored. This should encourage clinicians to consider using exercise therapy as an important treatment for functional scoliosis.

Extreme care was taken in the present study to control testing procedures and the conduct of the treatment programme itself. It is admissible, where other outcomes are the focus, to be less rigorous with respect to the treatment itself. Thus Stone et al (1979), had subjects perform an active exercise programme at home with no supervision, as opposed to the individual attention given to each subject in the present study. However, it is the author's opinion that without individual supervision, no valid information on the effect of exercise programmes on functional scoliosis can be achieved.
The information presented here is an attempt to show the responses of the functional scoliotic spine to an individualised and closely supervised exercise programme. This knowledge may provide a useful basis for better understanding and management of functional scoliosis, and might shed additional light on the effectiveness of exercise therapy in the treatment of this problem.

\section{REFERENCES}

1. Alter M J. Science of stretching. First Edition, Illinois: Campaign; 1988:1721.

2. Cailliet R. Scoliosis. First Edition, Philadelphia. F A Davie; 1975:12-43.

3. Cobb J R. Scoliosis. Journal of Bone and Joint Surgery 1958;40(A):510-512.

4. Janda $V$. On the concept of postural muscles and posture in man. Australian Journal of Physiotherapy 1983;29(1):83-85.

5. Keim H R. The adolescent spine. First Edition, New York: Springer-Verlag;1983:25-62.

6. Kisner C, Colby L A. Therapeutic exercise. Second Edition, Philadelphia: Davis F A; 1985:509-542.

7. Loncar D M, Pecina M, Preberg Z. A longitudinal study of growth velocity and development of secondary gender characteristics versus onset of idiopathic scoliosis. Clinical Orthopaedics 1991;270(1):278-282.

8. Nudelman W, Reis N D. Anatomy of the extrinsic spinal muscles related to the deformity of scoliosis. Acta Anatomica 1990;139(3):220-225.

9. Roaf R. Paralytic Scoliosis. Journal of Bone and Joint Surgery 1956;38(b):640-659.

10. Stone B, Beekman C, Hall V et al. The effect of an exercise program on change in curve in adolescents with minimal idiopathic scoliosis. Physical Therapy 1979;59(6):759-763.

11. Tarr I. Analysis of normal and scoliotic spine. Physiotherapy 1948;28(1):6-10.

12. Taylor J R. Scoliosis and growth. Patterns of asymmetry in normal vertebral growth. Acta Orthopaedica Scandinavica 1983;54(1):596-602.

13. Thompson C W. Manual of strictural kinesiology. Eleventh Edition. Boston; Times Mirror,1989:51-83.

\title{
THE SA JOURNAL OF PHYSIOTHERAPY IN THE INTERNATIONAL CONTEXT
}

\section{ay Lo-an Roux, Physiotherapy Publications}

In his last editorial after editing the New Zealand Journal of Physiotherapy for nine years, Bryan Paynter comments that on the occasion he "left out the editorial to see if anyone would notice, nobody said a word". He also comments that he is not certain that his wish that the Journal would be a vehicle of professional communication was fulfilled to the extent he desired.

And yet the index of articles in the December issue of the New Zealand Journal of Physiotherapy looks interesting enough:

- Study raises concern about concussion in rugby league games

- Neural involvement in shoulder pain

- Hypertrophy and hyperplasia in skeletal muscle following endurance training

- The effects of ultrasound on tumour growth and metastasis

- Physiotherapists rated positively by parents

- Overweight nurses suffer more back pain

- Clinical notes

- Working in the USA - a Kiwi perspective

- New directions for physiotherapy research.

Kathy Henderson is the Scientific Editor of the Australian Journal of Physiotherapy, and in her December editorial "Careful manuscript preparation maximises publication potential" she comments that "the majority of manuscripts are returned to the author(s) for revision" and that "a number of manuscripts require revision on more than one occasion prior to acceptance for publi- cation".

And yet the index of articles indicates that Australian physiotherapists are writing scientifically acceptable articles:

- Effect of trunk flexion speed on flexion relaxation of erector spinae

- Effect of age, gender and speed on three dimensional lumbar spine kinematics

- Group exercises for subjects with osteoarthritis of the knee

- Post stroke recovery of balanced sitting and ambulation ability

- Does laser enhance bruising in acute sporting injuries:

- Physiotherapy management of obstructed defaecation

- How to write a paper for a scientific journal.

The South African Journal of Physiotherapy has the same mission, methods and requirements as physiotherapy journals the world over. Even though it serves a relatively small local community of physiotherapists, it is also our professional showcase to the world. We know that South African physiotherapists are highly respected for the quality of papers presented at national and international congresses. The Journal is our vehicle for maintaining that respect between congresses.

The difficulties experienced by physiotherapists in writing for publication are universal. The difficulties experienced by journal editors in finding and shaping articles suitable for publication are universal. The "Guidelines for Authors", published by every journal in the world, invites and welcomes contributions. Your Journal is no exception! 